Published by Al-Nahrain College of Medicine P-ISSN 1681-6579

E-ISSN 2224-4719

Email: iraqijms@colmed-alnahrain.edu.iq

http://www.colmed-alnahrain.edu.iq

http://www.iraqijms.net

Iraqi JMS 2020; Vol. 18(2)

\title{
Is Dynamic Condylar Screw Better Than (95) Blade Plate in Management of Subtrochanteric Fracture of Femur?
}

\author{
Ahmed I. Joda ${ }^{1}$ FIBMS (Ortho), Zuhair A. Chhaily ${ }^{1}$ FIBMS (Ortho), Ahmed S. Abd Ali ${ }^{3}$ FIBMS \\ (Ortho), Laith S. Rahee ${ }^{1}$ FABHS (Ortho)
}

\begin{abstract}
${ }^{1}$ Section of Orthopedic, Dept. of Surgery, Al-Imamein Al-kadhimein Medical City, Baghdad, Iraq, ${ }^{2}$ Section of Orthopedic, Dept. of Surgery, College of Medicine, Al-Nahrain University, Baghdad, Iraq
\end{abstract}

\begin{abstract}
Background: Subtrochanteric fractures account for approximately 10-30\% of all hip fractures, affecting persons of all ages and should be internally fixed to reduce the morbidity and mortality by early rehabilitation and mobilization. A dynamic condylar screw (DCS) and a $95^{\circ}$ angle blade plate (BP) provide a good choice for fixation of subtrochanteric fractures so it is a matter of debate that which one is the best fixation in such fractures.

Objective: To evaluate the surgical treatment of subtrochanteric fracture of femur using DCS versus a $90^{\circ} \mathrm{BP}$.

Methods: $\quad$ Prospective comparative study of 40 patients conducted in Al-Imamein Al-Kadhimein Medical City from November 2015 to November 2017. Twenty patients treated with open reduction and internal fixation by using DCS and other twenty patients treated with open reduction and internal fixation by using a $95^{\circ} \mathrm{BP}$. The mode of injury, site and type of fracture, age of patients, operating time, and blood loss, union rate, complication of implants, functional results were compared between the groups.

Results: $\quad$ Out of 40 patients, there were $26(65 \%)$ male, right side affected in $24(60 \%)$ patients. Mechanism of injury was trivial trauma observed in $28(70 \%)$ patients. According to a Russell-Taylors classification, majority of fractures are type IB that observed in $16(40 \%)$ patients. Majority of the patients, $27(67.5 \%)$, started full weight bearing at 14 weeks. There was no significant mean age difference between the two groups $(p=0.7)$. The mean operation time of DCS $(83 \pm 4.3 \mathrm{~min})$ was lower significantly than of $95^{\circ} \mathrm{BP}(\mathrm{p}<0.001)$. Mean blood loss from DCS variety $(365 \pm 63 \mathrm{cc}$ ) was lower significantly than of $95^{\circ} \mathrm{BP}(\mathrm{p}=0007)$. Infection occurred less frequently significantly in patients who treated by DCS than those treated by $95^{\circ}$ BP $(p=0.03)$. There was no association between types of open reduction and internal fixation treatment variety and functional result according to the modified Harris hip score $(p=0.52)$.

Conclusion: $\quad$ DCS better than $95^{\circ}$ BP because of its technically easier, possibility to correct reduction even after insertion, less perioperative complication and earlier weight bearing.

Keywords: $\quad$ Subtrochanteric fractures of femur, dynamic condylar screw, $95^{\circ} \mathrm{BP}$

Citation: Joda AI, Chhaily ZA, Abd Ali AS, Rahee LS. Is dynamic condylar screw better than (95) blade plate in management of subtrochanteric fracture of femur? Iraqi JMS. 2020; 18(2): 123-129. doi: 10.22578/IJMS.18.2.6
\end{abstract}

List of abbreviations: $B P=$ Blade plate, $\mathrm{DCS}=$ Dynamic condylar screw, MHHS = Modified Harris Hip Score, ORIF = Open reduction internal fixation, RTA $=$ Road traffic accidents

\section{Introduction}

he subtrochanteric fracture of the femur is defined as a fracture that occurs in the proximal one-third of the femur from 
the center of lesser trochanter to center of isthmus of femur ${ }^{(1)}$. It occurs between lesser trochanter and a point $5 \mathrm{~cm}$ distally (2). Subtrochanteric fractures account for approximately $10-30 \%$ of all hip fractures, and they affect persons of all ages (3). These fractures occur in three specific patient populations: young patients involved in highenergy trauma, older osteoporotic patients involved in low-energy trauma, and patients exposed to chronic or high-dose bisphosphonate therapy. There is often overlap between the second and third patient population groups, as bisphosphonates are typically used to treat osteoporosis; however, patients with malignancies that are predisposed to bony metastasis occasionally fall into this category as well. Bisphosphonaterelated subtrochanteric fractures are often the result of low-energy trauma, but have also been reported as spontaneous fractures ${ }^{(2)}$.

The objective of this study is to evaluate the surgical treatment of subtrochanteric fracture of femur using dynamic condylar screw (DCS) versus a $95^{\circ}$ blade plate (BP).

\section{Methods}

Prospective comparative study was conducted from November 2015 to November 2017 at the Department of Orthopedic Surgery in AlImamein Al-Kadhimein Medical City, in which 40 patients with subtrochanteric fractures were recruited, twenty patients treated with open reduction internal fixation (ORIF) using DCS and other 20 patients treated with ORIF using a $95^{\circ} \mathrm{BP}$.

Inclusion criteria were Subtrochanteric fractures (occurs between lesser trochanter and a point $5 \mathrm{~cm}$ distally), type IA, IB, IIA and IIB classified according to Russell-Taylors classification. Skeletally mature patients (closed greater trochanter and femoral head physis). All patients have a closed fracture.

Exclusion criteria were multiple fractures in a limb or in-patient, presence of active local or remote infection, pathological fracture, and patient with sever medical comorbidities interfere with anesthesia.
The mode of injury, site and type of fracture, age of patients, operating time, and blood loss, union rate, complication of implants, functional result according to the MHHS were compared between the groups.

Data entry and analysis were performed using SPSS (Statistical Package for Social Sciences) version 24 and Microsoft excel. Means, stander deviation and frequencies were calculated for quantitative variables. Categorical data presented as frequency and percentage tables. A chi-square test of significance of association was performed to assess relations between categorical variables. Student t-test test the significant difference between the mean of two continuous variable. A level of $p$-value less than 0.05 was considered statistically significant.

\section{Results}

A total of 40 patients with subtrochanteric fractures were managed, (20) patients treated with ORIF using DCS and other (20) patients treated with ORIF using a $95^{\circ} \mathrm{BP}$, of which 14 (35\%) females and $26(65 \%)$ males, their mean age was $60.2 \pm 13.5$ years (range: $35-80$ years).

Of the total patients, right side affected in 24 (60\%) patients while $16(40 \%)$ patients got left side fracture. Mechanism of injury was trivial trauma, mostly falling on ground that observed in $28(70 \%)$ patients, road traffic accidents (RTA) observed in $12(30 \%)$ patients. Subtrochanteric fractures classified according to Russell-Taylors classification, out of (40) patients', majority of fractures are type IB that observed in 16 (40\%) patients, least number of cases was type IIB that observed in 2 (5\%) patients as shown in table (1).

Table (2) shows independent t-test to assess the difference of mean age between two variety of ORIF using DCS and a $95^{\circ} \mathrm{BP}$. There was no significant difference in mean age between patients treated by DSC and a $95^{\circ} \mathrm{BP}$ $(p=0.7)$. The mean operation time of DCS $(83 \pm 4.3 \mathrm{~min})$ was lower than for $95^{\circ} \mathrm{BP}$ and this relation was statistically significant $(p<0.001)$. Mean blood loss from DCS variety $(365 \pm 63.0$ $\mathrm{cc}$ ) was lower than for $95^{\circ} \mathrm{BP}$ and this relation was statistically significant $(p=0.007)$. 
Table 1. Distribution of the patients according to their mode of injury, site and type of fracture

\begin{tabular}{cccc}
\hline \multicolumn{2}{c}{ Patients medical characteristics } & Frequency & $\%$ \\
\hline \multirow{2}{*}{ Side of fracture } & Right & 24 & 60 \\
& Left & 16 & 40 \\
\hline \multirow{2}{*}{ Mode of injury } & Full on ground & 28 & 70 \\
& RTA & 12 & 30 \\
\hline \multirow{2}{*}{ Type of fracture } & IA & 3 & 7.5 \\
(Russell-Taylors & IB & 16 & 40 \\
classification) & IIA & 14 & 35 \\
& IIB & 2 & 5 \\
& Unclassified & 5 & 12 \\
\hline
\end{tabular}

RTA=Road traffic accidents

Table 2. Mean difference of age of patients, operating time and blood loss between Open Reduction Internal Fixation (ORIF) types

\begin{tabular}{|c|c|c|c|c|}
\hline Variable & Type of ORIF & Mean & \pm Std. Deviation & $P$ value \\
\hline \multirow{2}{*}{ Age } & DCS & 59.5 & 11.9 & \multirow{2}{*}{$0.7^{\mathrm{NS}}$} \\
\hline & $95^{\circ} \mathrm{BP}$ & 60.8 & 15.4 & \\
\hline \multirow{2}{*}{ Operating time ( $\min$ ) } & DCS & 83 & 4.3 & \multirow{2}{*}{$<0.001^{*}$} \\
\hline & $95^{\circ} \mathrm{BP}$ & 95 & 9.4 & \\
\hline \multirow{2}{*}{ Blood loss (cc) } & DCS & 365 & 63 & \multirow{2}{*}{$0.007^{*}$} \\
\hline & $95^{\circ} \mathrm{BP}$ & 440 & 99.4 & \\
\hline
\end{tabular}

*Significant association $(\mathrm{p}<0.05), \mathrm{NS}=$ non-significant, DCS=Dynamic condylar screw, BP=Blade plate

Infection occurred less frequently in patients who treated by DCS (1 case) than those treated by $95^{\circ}$ BP (6 cases), all were superficial infection and were treated with antibiotics and not required debridement or implant removal and this relation was statistically significant $(p=0.03)$ (Table 3).

Table 3. Relationship between types of Open Reduction Internal Fixation (ORIF) and infection rate of the patients

\begin{tabular}{|c|c|c|}
\hline \multirow{2}{*}{ Types of ORIF } & \multicolumn{2}{|c|}{ Infection rate } \\
\hline & Yes & No \\
\hline \multirow{2}{*}{ DCS } & 1 & 19 \\
\hline & $5 \%$ & $95 \%$ \\
\hline \multirow{2}{*}{$95^{\circ} \mathrm{BP}$} & 6 & 14 \\
\hline & $30 \%$ & $70 \%$ \\
\hline$P$ value & \multicolumn{2}{|c|}{$0.03^{*}$} \\
\hline
\end{tabular}

*Significant association $(p<0.05), D C S=$ Dynamic condylar screw, BP=Blade plate 
Mean time of union rate for patients who treated by DCS $(15.75 \pm 2.4)$ weeks ranged from (12-20) weeks, while for cases treated with $95^{\circ}$ BP the mean time for union was $(17.5 \pm 3.1)$ weeks ranged from (14-22) weeks, which is statistically not significant with p-value (0.07) as shown in table (4).

Table 4. Relationship between types of Open Reduction Internal Fixation (ORIF) according to the union rate

\begin{tabular}{cccc}
\hline Type of ORIF & Mean (weeks) & Std. Deviation (weeks) & Range (weeks) \\
\hline DCS & 15.75 & 2.4 & $12-20$ \\
$95^{\circ} \mathrm{BP}$ & 17.5 & 3.1 & $14-22$ \\
\hline p-value & \multicolumn{3}{c}{$0.07^{\mathrm{NS}}$} \\
\hline NS=non-significant $\mathrm{DCS}=$ Dynamic condylar screw, $\mathrm{BP}=$ Blade plate
\end{tabular}

$\mathrm{NS}=$ non-significant, $\mathrm{DCS}=$ Dynamic condylar screw, BP=Blade plate

Out of 20 cases treated with DCS, (1 case) (5\%) was ended with superior cut out while in 20 cases treated with $95^{\circ}$ BP ( 1 case) (5\%) ended with plate breakage and ( 1 case) ended with varus deformity and shortening about $2 \mathrm{~cm}$. This result was statistically not significant with p-value of (0.2) as shown in table (5).

Table 5. Relationship between types of Open Reduction Internal Fixation (ORIF) according to the complication of implants

\begin{tabular}{|c|c|c|c|}
\hline \multirow{2}{*}{ Types of ORIF } & \multicolumn{3}{|c|}{ Complication of implant } \\
\hline & Cut through & Breaking of plate & Malunion and shortening \\
\hline \multirow{2}{*}{ DCS } & 1 & 0 & 0 \\
\hline & $5 \%$ & $0 \%$ & $0 \%$ \\
\hline \multirow{2}{*}{$95^{\circ} \mathrm{BP}$} & 0 & 1 & 1 \\
\hline & $0 \%$ & $5 \%$ & $5 \%$ \\
\hline$P$ value & \multicolumn{3}{|c|}{$0.2^{\mathrm{NS}}$} \\
\hline
\end{tabular}

NS=non-significant, DCS=Dynamic condylar screw, BP=Blade plate

In the current study, functional outcome assessed based on modified Harris hip score that applied at the end of 6 months. There were 6 (30\%) patients with DCS and 3 (15\%) patients with $95^{\circ} \mathrm{BP}$ showed excellent results. Good results observed in $8(40 \%)$ patients with DCS and 7 (35\%) in $95^{\circ}$ BP group. Fair results observed in three $(15 \%)$ patients with DCS, 5 (25\%) patients in $95^{\circ} \mathrm{BP}$ group. Poor results were two (10\%) in patients with DCS, $4(20 \%)$ patients in $95^{\circ} \mathrm{BP}$ group. Failed result were one $(5 \%)$ in patients with DCS, and same result in patients with $95^{\circ} \mathrm{BP}$ group.

Table (6) shows Pearson Chi square test that test the significance of association between types of ORIF and functional result according to the Modified Harris Hip Score (MHHS).

There was no association between types of ORIF treatment variety and functional result according to the MHHS ( $p=0.52)$. 
Iraqi JMS 2020; Vol. 18(2)

Table 6. Relationship between types of Open Reduction Internal Fixation (ORIF) and functional result according to the Modified Harris Hip Score (MHHS)

\begin{tabular}{|c|c|c|c|c|c|}
\hline \multirow{2}{*}{ Types of ORIF } & \multicolumn{5}{|c|}{ Functional result according to the MHHS } \\
\hline & Excellent & Good & Fair & Poor & Failed \\
\hline \multirow{2}{*}{ DCS } & 6 & 8 & 3 & 2 & 1 \\
\hline & $30 \%$ & $40 \%$ & $15 \%$ & $10 \%$ & $5 \%$ \\
\hline \multirow{2}{*}{$95^{\circ} \mathrm{BP}$} & 3 & 7 & 5 & 4 & 1 \\
\hline & $15 \%$ & $35 \%$ & $25 \%$ & $20 \%$ & $5 \%$ \\
\hline
\end{tabular}

*Significant association ( $p<0.05$ ), NS=non-significant, DCS=Dynamic condylar screw, BP=Blade plate

\section{Discussion}

Subtrochanteric fractures account for approximately $10-30 \%$ of all hip fractures, and they affect persons of all ages (4). The characteristic anatomy, the biomechanical stress and forces acting at the subtrochanteric region makes it difficult to manage these fractures ${ }^{(3)}$.

In current study, the average age was 60.2 years (ranges: $34-80$ years), most of them were elderly patients, which was comparable with Sn et al. ${ }^{(4)}$.

Present study found that male was predominant (65\%), which was similar to what was found by Sn et al. who reported $(85 \%)$ of the patients were male (4).

Current study found that most of the side that affected was right; Chaturvedi et al. ${ }^{(5)}$ reported similar result.

In this study, the mechanism of injury was trivial trauma, mostly falling on ground in $70 \%$ of the injuries. This may be due to most of patient were elderly osteoporotic patients, which was in agree with what was found by Chaturvedi et al. ${ }^{(5)}$.

In this study, the mean operating time (from skin incision to skin closure) was 83 minutes for the DCS, which was more than for $95^{\circ} \mathrm{BP}$ (95 minutes), this due to easier operative technique for DCS, while BP need additional exposure to place plating and accurate reduction. This result was comparable to Halwai et al. who reported $80 \mathrm{~min}$ for the DCS (6). While Sharma et al. reported $92.2 \mathrm{~min}$ duration of surgery with DCS (7). Similarly, Neher et al. reported the duration as 108 min of surgery with $95^{\circ} \mathrm{BP}{ }^{(8)}$. Also, in agreement with present study, Vashisht et al. reported mean duration of surgery for DCS was 82.2 minutes (Range 72-90), mean duration of surgery for $95^{\circ} \mathrm{BP}$ was 104.47 minutes (Range 95-115) ${ }^{(9)}$.

In present study, regarding blood loss intraoperatively in DCS about $365 \mathrm{cc}$, while in $95^{\circ} \mathrm{BP}$ about $440 \mathrm{cc}$, this due to large incision and more manipulation in BP group. This comparable to Vashisht et al. who reported that average amount of blood loss was 380.33 Cc (Range 320-420) in cases treated with $95^{\circ} \mathrm{BP}$ and $342.67 \mathrm{cc}$ (Range 320-380) in cases treated with DCS ${ }^{(9)}$.

Neher et al. showed $418 \mathrm{cc}$ of blood loss during surgery with $95^{\circ}$ angle BP (8), while Mousa reported $250 \mathrm{cc}$ of blood loss during surgery with DCS (10).

This study showed that there are seven cases of infection, one from DCS (5\%) and six from $95^{\circ} \mathrm{BP}(30 \%)$, all were superficial infection and treated with antibiotics; none required debridement or implant removal. this due to excessive manipulation and longer operative time in BP group. This is comparable to Vashisht et al. who reported that infection occurred in one (6.67\%) case of $95^{\circ}$ BP group while none occurred in DCS group ${ }^{(9)}$.

Current study found that the mean time of union is 15.75 weeks for group treated with DCS \& 17.5 weeks for group treated with $95^{\circ}$ $\mathrm{BP}$, there were no significant statistical differences of the mean time union between groups ( $p$ value 0.07 ). This was agreed with Vashisht et al. who reported that radiological 
union in most of the patients (14 out of 15 cases) treated with DCS plate occurred between 12-16 weeks, while in cases treated with $95^{\circ} \mathrm{BP}$ radiological union in most of the patients (13 out of 15) occurred between 14-18 weeks ${ }^{(9)}$. Rohilla et al. showed that union in 16 weeks (11), Neogi et al. in 15.6 weeks (12), Laghari et al. in 16.5 weeks with DCS (13). Boopalan et al. showed that union in 16 weeks (14), Yoo et al. showed union in 19 weeks (15) and Laghari et al. showed union occurred in 18 weeks with $95^{\circ} \mathrm{BP}{ }^{(16)}$.

This study showed that the majority of patients $75 \%$ with DCS and $60 \%$ with $95^{\circ}$ BP had a full weight bearing at 14 weeks. Vashisht et al. reported full weight bearing was started at 1218 weeks in most of the patients (14 out of 15 cases) treated with $95^{\circ} \mathrm{BP}$, while in cases treated with DCS full weight bearing was started at 14-20 weeks in most of the patients (13 out of 15$)^{(9)}$.

In present study, functional outcome assessed based on modified Harris hip score, 30\% of patients with DCS and $15 \%$ of patients with $95^{\circ}$ BP showed excellent results. Good results were $40 \%$ in DCS and $35 \%$ in CBP group. Fair results were $15 \%$ in DCS, $25 \%$ in $95^{\circ} \mathrm{BP}$ group. Poor results were $10 \%$ in DCS, $20 \%$ in CBP group, and failed result were equally in both group (5\% with each of them). Overall, $22.5 \%$ showed excellent, $37.5 \%$ good, $20 \%$ fair, $15 \%$ poor results and $10 \%$ failed result. Vashisht et al. (9) stated that out of 15 patients reported excellent results were seen in $3(20 \%)$ cases of $95^{\circ}$ BP group and 5 (33.33\%) cases of DCS group. Results were good in $7(46.66 \%)$ cases of $95^{\circ} \mathrm{BP}$ group and $9(60 \%)$ cases of DCS group. 3 (20\%) patients had fair result in the $95^{\circ} \mathrm{BP}$ group. While poor results seen in two (13.33\%) cases of $95^{\circ} \mathrm{BP}$ group, one (6.67\%) patient had poor result in the DCS group.

Halwai et al. showed excellent to good results in $73.33 \%{ }^{(6)}$, Neogi et al. in $95 \%$ cases ${ }^{(12)}$, Laghari et al. in $81 \%$ cases with DCS ${ }^{(16)}$. Laghari et al. also showed excellent to good results in $78.56 \%$ cases with $95^{\circ} \mathrm{BP}(16)$

Current study reported that one case $2.5 \%$ with malalignment with both groups this occur with $95^{\circ} \mathrm{BP}$ group. Chaturvedi et al. reported varus angulation in one case fixation of fracture with DCS (5).

This study had concluded that a DCS will be a good option for treatment of subtrochanteric femoral fractures, which is better than the $95^{\circ} \mathrm{BP}$ and that because of the following:

1-It is technically easier than $95^{\circ} \mathrm{BP}$.

2-Possibility to correct the reduction even after insertion of condylar screw.

3-Less perioperative complications as infection \& blood loss and less operative time.

4-It has had earlier radiological union and earlier weight bearing.

Although the $95^{\circ} \mathrm{BP}$ remains as alternative option for the internal fixation of subtrochanteric femoral fracture.

For further research, large population-based studies are recommended in order to determine the scope of this problem nationwide and a follow up study is needed to reach for the best methods for treatment of this type of fractures and to assess the relationship between the variables over time.

\section{Acknowledgement}

The authors are most grateful and would like to express thanks to the assistants' medical staff of operating theater.

\section{Author contribution}

The patients were operated on and followed for their outcome by Dr. Joda, Dr. Rahee, Dr. Abd Ali, and Dr. Chhaily. Research conduction and statistical analysis done by Dr. Abd Ali.

\section{Conflict of interest}

There was no conflict of interest.

\section{Funding}

The authors offer all funding for the research.

\section{References}

1. Babhulkar SS. Subtrochanteric fractures of the femur. In: Kulkarni GS, Babhulkar (ed). Textbook of orthopedics and trauma. $2^{\text {nd }}$ ed. New Delhi: Jaypee; 2008. p. 2074-88.

2. Sassoon AA, Langford J, Haidukewych GJ. Subtrochanteric femur fractures. In: Court-Brown C, Heckman JD, McKee M, et al (eds), Rockwood and Green's Fractures in adults, $8^{\text {th }}$ ed. Philadelphia: Wolters Kluwer; 2015. p. 2131-47. 
3. Lee MA, Forsh DA, Ertl JP. Subtrochanteric hip fractures. Updated: Aug 25, $2020 . \quad$ URL: https://emedicine.medscape.com/article/1247329overview.

4. Sn S, Maniar PP, Moradiya N, et al. Outcome evaluation of dynamic condylar screw fixation for subtrochanteric femur fracture. Int J Ortho Sci. 2017; 3: 351-5. doi: 10.22271/ORTHO.2017.V3.I1F.52

5. Chaturvedi B, Banerjee S, Ali SKI. Study of internal fixation of subtrochantric fracture of femur by dynamic hip screw, dynamic condylar screw and proximal femur nail. Int J Sci Res Publ. 5(10): 22503153.

6. Halwai MA, Dhar SA, Wani MI, et al. The dynamic condylar screw in the management of subtrochanteric fractures: does judicious use of biological fixation enhance overall results. Strategies Trauma Limb Reconstr. 2007; 2(2): 77-81. doi: 10.1007/s11751-007-0022-8.

7. Sharma V, Sharma S, Singh N, et al. Management of subtrochanteric femoral fractures by dynamic condylar screw (DCS). Internet J Ortho Surg. 2008; 11(2).

8. Neher C, Ostrum RF. Treatment of subtrochanteric femur fractures using a submuscular fixed low-angle plate. Am J Orthop (Belle Mead NJ). 2003; 32(9 Suppl): 29-33.

9. Vashisht D, Sreen S, Daroch MS, et al. Dynamic condylar screws versus 950 angle blade plate fixation of subtrochantric fractures of femur. Int J Res Med Sci. 2017; 5(5): 2040-5. doi: https://dx.doi.org/10.18203/23206012.ijrms20171839.

10. Mousa SS. Results of biological fixation for subtrochanteric femoral fractures with a beveled dynamic condylar screw. Egypt Orthop J. 2014; 49: 140-5.

11. Rohilla R, Singh R, Magu NK, et al. Mini-incision dynamic condylar screw fixation for comminuted subtrochanteric hip fractures. J Orthop Surg (Hong Kong). 2008; 16(2): 150-5. doi: 10.1177/230949900801600204.

12. Neogi DS, Trikha V, Mishra KK, et al. Biological plate fixation of comminuted subtrochanteric fractures with the Dynamic Condylar Screw: a clinical study. Acta Orthop Belg. 2009; 75(4): 497-503.

13. Laghari MA, Makhdoom A, Pahore MK, et al. Subtrochanteric Femoral Fractures Treated by Fixation with Dynamic Condylar Screw System. JLUMHS. 2011; 10(3): 134.

14. Boopalan PR, Jepegnanam TS, Nithyananth $M$, et al. Functional outcome of biological condylar blade plating of subtrochanteric fractures. J Orthop Sci. 2012; 17(5): 567-73. doi: 10.1007/s00776-012-02446.

15. Yoo MC, Cho YJ, Kim KI, et al. Treatment of unstable peritrochanteric femoral fractures using a 95 degrees angled blade plate. J Orthop Trauma. 2005; 19(10): 687-92. doi: 10.1097/01.bot.0000184141.52330.5e.

16. Laghari MA, Makhdoom A, Pahore MK, et al. Subtrochanteric femoral fractures treated by condylar plate, a study of 56 cases. JLUMHS. 2012; 11(2): 54-9.

Correspondence to Dr. Ahmed I. Joda

E-mail: ahmedjoda79@yahoo.com

Received Sep. $6^{\text {th }} 2020$

Accepted Dec. $13^{\text {th }} 2020$ 